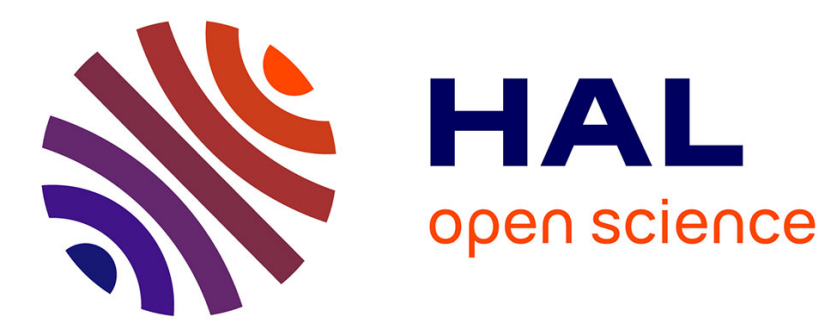

\title{
Rapid catalytic oxidation of arsenite to arsenate in an iron(III)/sulfite system under visible light
}

Jing Xu, Wei Ding, Feng Wu, Gilles Mailhot, Danna Zhou, Khalil Hanna

\section{To cite this version:}

Jing Xu, Wei Ding, Feng Wu, Gilles Mailhot, Danna Zhou, et al.. Rapid catalytic oxidation of arsenite to arsenate in an iron(III)/sulfite system under visible light. Applied Catalysis B: Environmental, 2016, 186, pp.56-61. 10.1016/j.apcatb.2015.12.033 . hal-01254801

\section{HAL Id: hal-01254801 \\ https://hal-univ-rennes1.archives-ouvertes.fr/hal-01254801}

Submitted on 24 Mar 2016

HAL is a multi-disciplinary open access archive for the deposit and dissemination of scientific research documents, whether they are published or not. The documents may come from teaching and research institutions in France or abroad, or from public or private research centers.
L'archive ouverte pluridisciplinaire HAL, est destinée au dépôt et à la diffusion de documents scientifiques de niveau recherche, publiés ou non, émanant des établissements d'enseignement et de recherche français ou étrangers, des laboratoires publics ou privés. 


\title{
Rapid catalytic oxidation of arsenite to arsenate in an iron(III)/sulfite system under visible light
}

\author{
Jing $\mathrm{Xu}^{\mathrm{a}, \mathrm{b}}$, Wei Ding ${ }^{\mathrm{a}}$, Feng Wu ${ }^{\mathrm{a}^{*}}$, Gilles Mailhot ${ }^{\mathrm{c}}$, Danna Zhou ${ }^{\mathrm{d}}$ Khalil Hanna ${ }^{\mathrm{b} *}$ \\ ${ }^{a}$ Department of Environmental Science, Hubei Key Lab of Biomass Resource Chemistry and \\ Environmental Biotechnology, School of Resources and Environmental Science, Wuhan \\ University, Wuhan, 430079, P. R. CHINA \\ ${ }^{\mathrm{b}}$ Ecole Nationale Supérieure de Chimie de Rennes, CNRS, UMR 6226, 11 Allée de Beaulieu, \\ CS 50837, 35708 Rennes Cedex 7, France \\ c Clermont Université, Université Blaise Pascal-ENSCCF, Institut de Chimie de \\ Clermont-Ferrand (ICCF), BP10448, F-63000 Clermont-Ferrand, France \\ ${ }^{\mathrm{d}}$ Faculty of Material Sciences and Chemistry, China University of Geosciences, \\ Wuhan, 430074, P. R. China \\ *Corresponding author. Tel: 86-27-68778511, Fax: 86-27-68778511, E-mail: fengwu@whu.edu.cn \\ **Corresponding author. Tel: +33(0)223238027, Fax: +33(0)223238120, E-mail: \\ khalil.hanna@ensc-rennes.fr
}




\section{Graphical abstract}

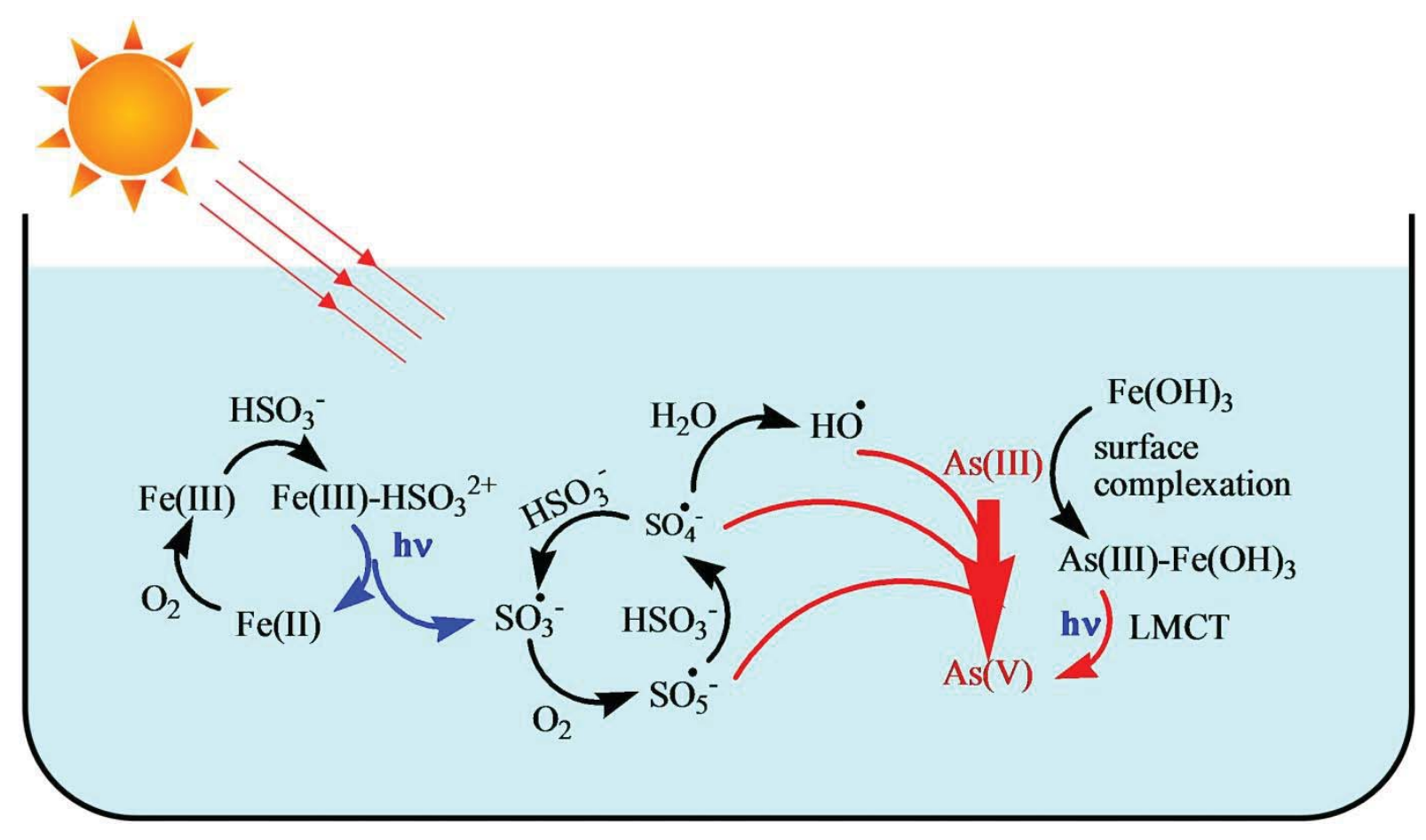

Highlights

- Visible light is efficient to induce As(III) oxidation in Fe(III)/sulfite system

- High oxidation and removal rates of As(III) is achieved at pH 6

- Mechanism of As(III) oxidation involved both hydroxyl and oxysulfur radicals

- $\quad$ As(III) can sorb to Fe-particles and then be oxidized through LMCT process

- Sequential addition of sulfite is beneficial to improve the As(III) oxidation.

\section{Abstract}

Removal of arsenic in industrial wastewaters proceeds often through oxidation of As(III) to $\mathrm{As}(\mathrm{V})$ following by precipitation and/or adsorption. In this work, the catalytic oxidation of 
$\mathrm{As}(\mathrm{III})$ to $\mathrm{As}(\mathrm{V})$ in an iron(III)/sulfite system and the removal of $\mathrm{As}(\mathrm{V})$ under visible light using sunlight or a light-emitting diode lamp were investigated. Our results show a significant enhancement of efficiency of As(III) oxidation at near-neutral pH, whereas 93\% of As(III) was removed from solution by centrifugal treatment after 30 min of irradiation. Mechanism investigations revealed that the pathways of As(III) oxidation at circumneutral $\mathrm{pH}$ involved free radicals (mainly $\mathrm{HO} \bullet \mathrm{SO}_{4}^{-} \bullet$ and $\mathrm{SO}_{5}{ }^{-}$) and ligand-to-metal charge transfer between As(III) and colloidal ferric hydroxide particles. Sequential addition of sulfite could improve the oxidation efficiency for water having high concentrations of As(III) (i.e., $66.7 \mu \mathrm{M}$ ). These results clearly show that the visible light/iron(III)/sulfite system significantly enhances As(III) oxidation. This finding may have promising implications in developing a new cost-effective technology for the treatment of arsenic-containing water using sunlight.

Keywords: arsenic; iron(III)/sulfite; solar light; photooxidation; oxysulfur radicals.

\section{Introduction}

Arsenic contamination has drawn much attention worldwide for many years. The distribution of arsenic species determines not only their behavior and toxicity in various environmental media [1,2], but also methods of their removal from contaminated waters and soils [3]. Since the toxicity of inorganic arsenite (As(III)) is higher than that of inorganic arsenate $(\mathrm{As}(\mathrm{V}))$, detoxification of arsenic by oxidation of $\mathrm{As}(\mathrm{III})$ to $\mathrm{As}(\mathrm{V})$ [4-6] is often considered before removing it from industrial wastewater by precipitation, filtration, or adsorption $[7,8]$. Among the classical oxidants, chlorine, ozone, potassium permanganate 
( $\mathrm{KMnO}_{4}$ ), and persulfate (PS) [7-9] have been widely used for As(III) oxidation. Some catalyzed oxidation systems such as Fenton reaction [6,10], metal-activated PS [11], and $\mathrm{TiO}_{2}$ photocatalytic [12,13] systems have been applied to the oxidation of As(III). Moreover, energy (e.g., light [14,15], ultrasonic waves [16], and electricity [17]) has been utilized to enhance As(III) oxidation. Hydroxyl radical (HO•) [15,18-20], superoxide [13], and sulfate radical $\left(\mathrm{SO}_{4}{ }^{-} \cdot\right)[21,22]$ are potential species for the oxidation of As(III). In particular, HO• with As(III) has a very high second-order rate constant (Eq. (1)) at low pH (2-5.6) [23]. Second-order rate constants of the reaction between $\mathrm{SO}_{4}{ }^{-} \bullet$ and As(III) are also very high (Eq. (2)) [21,22]. Therefore, both $\mathrm{HO} \bullet$ and $\mathrm{SO}_{4}{ }^{-}$radicals may oxidize $\mathrm{As}(\mathrm{III})$.

$$
\begin{array}{ll}
\mathrm{As}(\mathrm{OH})_{3}+\mathrm{HO} \bullet \rightarrow \mathrm{As}(\mathrm{OH})_{4} & k_{1}=8.5 \times 10^{9} \mathrm{M}^{-1} \mathrm{~s}^{-1} \quad[23] \\
\mathrm{As}(\mathrm{III})+\mathrm{SO}_{4}{ }^{-} \bullet \rightarrow \mathrm{As}(\mathrm{IV})+\mathrm{SO}_{4}{ }^{2-} & k_{2}=\sim 6.1 \times 10^{9} \mathrm{M}^{-1} \mathrm{~s}^{-1}[21,22]
\end{array}
$$

Although $\mathrm{SO}_{4}{ }^{-} \bullet$-based advanced oxidation processes (S-AOPs) have drawn great attention in recent decades [22,24,25], little is known about the mechanism of As(III) oxidation by S-AOPs and the nature of the reactive oxygen species involved. The system using sulfite (generally expressed as S(IV)) as reactant and iron(II), iron(III), or light as inductor can also produce $\mathrm{SO}_{4}{ }^{-}$[26]. Recently, iron(II)/(III)-sulfite systems with or without UV light have been used to decolorize azo dyes, but dye mineralization in such systems is very poor [27-30]. Although As(III) can be oxidized in such systems with or without UV light [31-33], the possibility of utilizing Fe-sulfite system for rapid As(III) oxidation under visible light (e.g., sunlight) has not been explored. Furthermore, the mechanisms of As(III) oxidation by generated oxysulfur radicals (e.g. $\mathrm{SO}_{3}{ }^{-} \bullet, \mathrm{SO}_{4}{ }^{-} \bullet$, and $\mathrm{SO}_{5}{ }^{-} \bullet$ ) are still unclear. Therefore, the present work aimed to determine the mechanism of As(III) oxidation at circumneutral $\mathrm{pH}$ in an 
iron-catalyzed sulfite system using visible light. In order to determine the role of different oxysulfur radicals in the reaction, radical scavengers, an iron-complexing agent and nitrogen gas were used. Our work may contribute to an understanding of the main mechanisms of As(III) removal using an iron-sulfite system and may aid development of new As(III) decontamination methods driven by visible light.

\section{Materials and Methods}

\subsection{Chemicals}

Ultrapure water obtained from a water purification system (Liyuan Electric Instrument Co., Beijing, China) was used in the experiments. $\mathrm{NaAsO}_{2}$ (99.5\%; Gracia Chemical Technology Co. Ltd., Chengdu, China) was used after $24 \mathrm{~h}$ of drying in desiccators. $\mathrm{Na}_{2} \mathrm{HAsO}_{4} \cdot 7 \mathrm{H}_{2} \mathrm{O}$ was purchased from Alfa Aesar (Ward Hill, MA). $\mathrm{Na}_{2} \mathrm{SO}_{3}$ (analytical reagent (AR)) was purchased from Sinopharm Chemical Reagent Co., Ltd., (Shanghai, China) and was used without further purification, the stock solution was freshly prepared before each experiment. tert-Butyl alcohol (TBA, AR) was purchased from Shanghai Shiyi Chemicals Reagent Co. Ltd., and ethanol (EtOH, AR) was obtained from Tianjin Kermel Chemical Reagent Co. Ltd. 5,5-Dimethyl-1-pyrroline $N$-oxide (DMPO) was purchased from J\&K Scientific Co. Ltd. To prepare $100 \mathrm{~mL}$ of Fe(III) stock solution, $0.39 \mathrm{~g}$ of $\mathrm{Fe}_{2}\left(\mathrm{SO}_{4}\right)_{3}$ (AR; Taishan Chemicals Reagent Co. Ltd.) was weighed into a $100 \mathrm{~mL}$ beaker containing $50 \mathrm{~mL}$ of ultrapure water and $5 \mathrm{~mL}$ of $\mathrm{H}_{2} \mathrm{SO}_{4}$ solution (98\%, Sinopharm Chemical Reagent Co., Ltd). After complete dissolution and cooling, the mixture was diluted to $100 \mathrm{~mL}$ with ultrapure water. All the other reagents were analytically pure (except $\mathrm{KBH}_{4}$ (95\%) and formaldehyde (37\%)) and were obtained from 
Sinopharm Chemical Reagent Co., Ltd. All prepared solutions were protected from light and stored at $4^{\circ} \mathrm{C}$.

\subsection{Photooxidation reaction system and batch experiments}

Batch experiments (except solar irradiation experiments) were conducted in a $500 \mathrm{~mL}$ cylindrical, hollow cooling equipment at $25^{\circ} \mathrm{C}$ in the dark or under irradiation by four light-emitting diodes $(\lambda=404 \mathrm{~nm}$; emission spectrum is shown in Figure S1 in the Supporting Information). The irradiation system is described in detail in our previous work [34]. A pH meter (PHS-3C, Aolilong Co. Ltd., Hangzhou, China) and a dissolved oxygen (DO) meter (8403, AZ Instrument Co. Ltd., Taiwan, China) was placed in the beaker to determine the $\mathrm{pH}$ and DO values before and during reactions. The solutions were stirred continuously by a magnetic stirrer. Predetermined amounts of As(III) and Fe(III) were diluted in a $500 \mathrm{~mL}$ flask and transferred to a beaker after complete mixing. The $\mathrm{pH}$ value of the mixture was adjusted to slightly lower than the desired value with diluted $\mathrm{NaOH}$ and $\mathrm{H}_{2} \mathrm{SO}_{4}$ solutions. Fresh $\mathrm{Na}_{2} \mathrm{SO}_{3}$ solution was added to this reaction solution to reach the desired $\mathrm{pH}$ value, and then lamps were switched on. At specified time intervals, a certain amount of the solution sample was collected for analysis. Batch experiments were all conducted under the irradiation of LED lamps unless otherwise stated.

In sunlight-induced oxidation experiments, sunlight was used instead of LED lamps for irradiation, and all other procedures remained the same as in previous batch experiments. Sunlight-induced oxidation experiments were conducted at different times during a day in order to simulate different light intensities as previously reported [35]. 
In $\mathrm{N}_{2}$ purging experiments, the top of the cylinder reactor was sealed with a rubber stopper. Purging of solutions with high-purity $\mathrm{N}_{2}$ (99.99\%) was performed for 30 min before reactions and was continued during reactions to ensure that oxygen was excluded.

Iron speciation (i.e., dissolved ion vs. solid form) at various $\mathrm{pH}$ values was determined. A $0.1 \mathrm{mM}$ iron(III) solution with initial $\mathrm{pH}$ of 2.0 was prepared. The $\mathrm{pH}$ was adjusted to desired values, and then $10 \mathrm{~mL}$ of the resulting mixture was drawn for centrifugation at $9000 \mathrm{rpm}$ for 15 min. Subsequently, the supernatant was used to determine the concentration of dissolved iron.

In experiments on arsenic removal, samples after reaction were taken and centrifuged for $15 \mathrm{~min}$ at $9000 \mathrm{rpm}$. The supernatant was used to determine the residual concentration of arsenic in solution.

\subsection{Analytical methods}

Total As(III), As(T) (As(III) + As(V)), and iron species concentrations were determined as explained in our previous works [34,36]. Withdrawn samples were diluted with $1.5 \% \mathrm{HCl}$ (for As(III) determination) or 5\% $\mathrm{HCl}$ (for $\mathrm{As}(\mathrm{T})$ determination) solution. Sample dilution and $\mathrm{pH}$ lowering stopped arsenic oxidation, as proven by experimental results at $\mathrm{pH} 1$ under irradiation; results show negligible oxidation of arsenic under extreme acidic conditions. Moreover, acidic conditions led to the dissolution of iron hydroxide colloids and arsenic species. Arsenic concentration was determined by using hydride generation atomic fluorescence spectrometry (HG-AFS) (Titan Instrument Co. Ltd., Beijing, China). As(III) was determined by using 1.5\% $\mathrm{HCl}-1.5 \% \mathrm{KBH}_{4}$ solution, and $\mathrm{As}(\mathrm{T})$ was determined by using $1 \%$ thiourea $\left(\mathrm{m} \mathrm{V}^{-1}\right)-1 \%$ ascorbic acid $\left(\mathrm{m} \mathrm{V}^{-1}\right.$ ) and $5 \% \mathrm{HCl}-2 \% \mathrm{KBH}_{4}$ solutions. Prior to $\mathrm{As}(\mathrm{T})$ determination by 
HG-AFS, thiourea and ascorbic acid were used to reduce As(V) to As(III) [37], then $\mathrm{KBH}_{4}$ and $\mathrm{HCl}$ were used for hydrogenating $\mathrm{As}(\mathrm{III})$ to $\mathrm{AsH}_{3}$ [38]. Fe(II) concentration was determined by spectrophotometry (Shimadzu UV-1601) at $510 \mathrm{~nm}$ using 1,10 phenanthroline method [36]. For determination of Fe(III) and then total Fe concentrations, ascorbic acid was used to reduce Fe(III) to Fe(II). The experiment was conducted at least twice, and the error for each sample is shown in figures in the results section.

In sunlight-induced oxidation experiments, a solar power meter (SM206, Shenzhen Sanpometer Ltd., Shenzhen, China) was used to determine the irradiation flux of solar power. To compare the reaction rate constants under different conditions, pseudo-first-order equation was used to fit the kinetic data. The pseudo-first-order equation can be expressed as: $\ln \left(C / C_{0}\right)=$ $-k_{\text {app }} t$, where $C_{0}$ and $C$ are the concentrations at initial time and any reaction time t, respectively. $k_{\text {app }}\left(\mathrm{min}^{-1}\right)$ was calculated from the slope of the plots of $\ln \left(C / C_{0}\right)$ vs. $t$. Due to the complexity of oxidation mechanisms and fast consumption of sulfite in the iron(III)/sulfite-visible light system, the equation applied only to the data obtained in the first 5 min.

\section{Results and discussion}

\subsection{Effect of visible irradiation}

As shown in Figure 1, As(III) was oxidized slowly in the iron(III)/sulfite system at circumneutral $\mathrm{pH}$ in the dark. The oxidation efficiency was significantly improved under LED lamps irradiation: 74\% of As(III) was oxidized within 10 min. Blank experiments (Figure 1) showed no As(III) oxidation in the absence of Fe(III), indicating that sulfite did not generate oxysulfur radicals via direct photolysis. However, $45 \%$ of As(III) was oxidized in the presence of Fe(III) in the absence of sulfite within 30 min. Colloidal ferric hydroxides (CFH) can form at 
near-neutral pH conditions (See Table S1) and thus sorb As(III) through surface complexation $[39,40]$. As(III) can then be oxidized by electron transfer from As(III) to Fe(III) induced by radiation absorption via ligand-to-metal charge transfer (LMCT), as previously reported [34]. Consequently, the decrease in total As(III) concentration determined after sample acidification (Figure 1) may be due to radical oxidation pathway of As(III) and also adsorption on CFH followed by oxidation. The difference between the total As concentration and total As(III) concentration corresponds to the oxidation of As(III) to As(V) (Figure S2).

Because the treatment of arsenic containing wastewater must include not only the oxidation of As(III) to As(V) but also the removal of final product (i.e. As(V)), centrifugation at 9000 rpm for 15 min was conducted to assess the removal of arsenic from aqueous phase. After photo-iron(III)/sulfite treatment, the most of As(III) was oxidized to the less soluble form $\mathrm{As}(\mathrm{V})$, that was then removed by precipitation/adsorption to CFH. It should be noted that both $\mathrm{As}(\mathrm{V})$ and $\mathrm{As}(\mathrm{III})$ were removed by combining oxidation and centrifugation process. Approximately $94 \%$ of total arsenic were removed from solution (Table S2), which is close to the amount of Fe(III) ( 96\% of $0.1 \mathrm{mM}$ ) precipitated at pH 6 (Table S1).

In the iron(II)/sulfite system, DO takes part in the oxidation of Fe(II) and sulfite via Eqs. (4) and (7) $[41,42]$. Here, iron recycling and generation of oxysulfur radicals rely on the presence of oxygen (Eqs. (5)-(8)) [43]. The variation of DO content in the iron(III)/sulfite system at initial $\mathrm{pH}$ of 6 between dark and light conditions was compared (Figure S3a). In the dark condition, the DO content slightly increased because of reoxygenation. Under irradiation, the DO content sharply declined, suggesting formation of free radicals (Eqs. (7)-(10)) and oxidation of reduced Fe(II) (Eq. (4)), which would increase the efficiency of oxidation. In the 
latter stage of the reaction, sulfite consumption (Figure S3b) and reoxygenation may explain the small increase in DO content.

$$
\begin{aligned}
& \mathrm{Fe}^{2+}+\mathrm{HSO}_{3}{ }^{-} \rightarrow \mathrm{FeHSO}_{3}{ }^{+} \quad \log \mathrm{K}_{3}=4 \quad[41,42] \\
& 4 \mathrm{FeHSO}_{3}{ }^{+}+\mathrm{O}_{2} \rightarrow 4 \mathrm{FeSO}_{3}{ }^{+}+2 \mathrm{H}_{2} \mathrm{O} \text { (rapid equilibrium) } \quad[41,42] \\
& \mathrm{Fe}^{3+}+\mathrm{SO}_{3}^{2-} \rightarrow \mathrm{FeSO}_{3}^{+} \quad \text { (fast) [43] } \\
& \equiv \mathrm{Fe}(\mathrm{III})+\mathrm{SO}_{3}{ }^{2-} \rightarrow \equiv \mathrm{Fe}(\mathrm{III})\left(\mathrm{SO}_{3}{ }^{2-}\right) \\
& \mathrm{FeSO}_{3}{ }^{+} \rightarrow \mathrm{Fe}^{2+}+\mathrm{SO}_{3}{ }^{-} \quad k_{6}=0.19 \mathrm{~s}^{-1} \quad \text { (rate-limiting step) [43] } \\
& \mathrm{SO}_{3}{ }^{-} \bullet+\mathrm{O}_{2} \rightarrow \mathrm{SO}_{5}^{-} \bullet \quad k_{7}=(1-2.3) \times 10^{9} \mathrm{M}^{-1} \mathrm{~s}^{-1} \\
& \mathrm{SO}_{5}{ }^{-} \bullet+\mathrm{HSO}_{3}{ }^{-} \rightarrow \mathrm{SO}_{4}{ }^{2-}+\mathrm{SO}_{4}^{-} \bullet+\mathrm{H}^{+} \quad k_{8}=\left(10^{4}-10^{7}\right) \mathrm{M}^{-1} \mathrm{~s}^{-1} \quad \text { [43] } \\
& \mathrm{SO}_{4}{ }^{-} \bullet+\mathrm{H}_{2} \mathrm{O} \rightarrow \mathrm{SO}_{4}{ }^{2-}+\mathrm{HO} \bullet+\mathrm{H}^{+} \quad k 9=6.6 \times 10^{2} \mathrm{M}^{-1} \mathrm{~s}^{-1}[44] \\
& \mathrm{SO}_{4}{ }^{-} \bullet+\mathrm{OH}^{-} \rightarrow \mathrm{SO}_{4}{ }^{2-}+\mathrm{HO} \cdot k_{10}=1.4 \times 10^{7} \mathrm{M}^{-1} \mathrm{~s}^{-1}
\end{aligned}
$$

The $\mathrm{pH}$ variation relative to the DO content in the dark differed from that under light conditions (Figure S3c). The pH significantly changed only under irradiation, decreasing sharply in the first 10 min and then very slowly at a later stage because of sulfite consumption (Figure S3b). The decrease in $\mathrm{pH}$ may be explained by Eq. (8), thereby corroborating the formation of oxidizing radical species.

To verify whether the solar power can also promote As(III) oxidation in the iron(III)/sulfite system, experiments were performed under three different intensities of sunlight. The initial pseudo-first-order apparent rate constants $k_{\text {app }}\left(\mathrm{min}^{-1}\right)$ show that As(III) can undergo oxidation in the iron(III)/sulfite system under solar irradiation (Figure 2). Under an average solar power of $26.8 \mathrm{~W} \mathrm{~m}^{-2}$, approximately $64 \%$ of As(III) was oxidized in $30 \mathrm{~min}$, whereas the efficiency of As(III) photooxidation was enhanced to 81\% within 10 min under an 
average solar power of $485 \mathrm{~W} \mathrm{~m}^{-2}$.

\subsection{Effect of sulfite dosage on As(III) oxidation}

Different amounts of sulfite were used to investigate the effect of sulfite dosage on As(III) oxidation at pH 6. $k_{\text {app }}$ values, determined as previously mentioned, were plotted against sulfite dosage in Figure 3. kapp values increased initially with the increase in sulfite dosage, reached a maximum value at $0.2 \mathrm{mM}$, and then decreased. According to Eqs. (5)-(10), sulfite-iron(III) complexes can undergo chain reactions that generate oxysulfur radicals and $\mathrm{HO} \cdot$, and increasing the sulfite concentration can improve the initial rate of oxidation. According to Eqs. (11) and (12), however, the generated radicals $\mathrm{SO}_{4}{ }^{-} \bullet$ and $\mathrm{HO} \bullet$ can be scavenged by sulfite when it is used at much higher concentrations.

$$
\begin{aligned}
& \mathrm{HSO}_{3}{ }^{-}+\mathrm{SO}_{4}{ }^{-} \bullet \rightarrow \mathrm{SO}_{4}{ }^{2-}+\mathrm{H}^{+}+\mathrm{SO}_{3}{ }^{-} \bullet \quad k_{11}=(0.5-2) \times 10^{9} \mathrm{M}^{-1} \mathrm{~s}^{-1} \quad \text { [28] } \\
& \mathrm{HSO}_{3}{ }^{-}+\mathrm{HO} \bullet \rightarrow \mathrm{H}_{2} \mathrm{O}+\mathrm{SO}_{3}{ }^{-} \bullet \quad k_{12}=4.5 \times 10^{9} \mathrm{M}^{-1} \mathrm{~s}^{-1} \quad \text { [28] }
\end{aligned}
$$

Variations of DO content and $\mathrm{pH}$ with the sulfite dosage were also determined (Figure S4a and b). The rate of DO depletion increased with the increase in sulfite dosage. When $\left[\mathrm{SO}_{3}{ }^{2-}\right]=0.8$ $\mathrm{mM}$, the DO content decreased rapidly from 6.68 to $0 \mathrm{mg} \mathrm{L}^{-1}$ within $10 \mathrm{~min}$. According to Eqs. (4) and (7), the depletion of DO observed at high dosage of sulfite could affect the generation of radicals and thus the rate of oxidation. Similarly, the $\mathrm{pH}$ decreased with increasing sulfite concentration, probably because of the generation of protons through Eqs. (8) and (11).

\subsection{Effect of $p H$ value on As(III) oxidation}

The effect of $\mathrm{pH}$ on As(III) oxidation kinetics with or without light was investigated over a wide $\mathrm{pH}$ range (3 - 8). Without irradiation, As(III) oxidation was significant at $\mathrm{pH} 3$, and then 
$k_{\text {app }}$ decreased with increase of $\mathrm{pH}$ (results of $k_{\text {app }}$ are shown in Figure 4). Irradiation did not affect $k_{\text {app }}$ significantly at $\mathrm{pH} 3$, however, in the $\mathrm{pH}$ range of $4-8$, $k_{\text {app }}$ was significantly enhanced by irradiation. The effect of the presence of sulfite is also different at various $\mathrm{pH}$ values (Figure 5). In the absence of sulfite, $k_{\mathrm{app}}$ increased slightly with increasing $\mathrm{pH}$. In the presence of sulfite, $k_{\text {app }}$ is significantly higher than that in the absence of sulfite over the whole $\mathrm{pH}$ range investigated. To explain this $\mathrm{pH}$-dependence, the mechanisms of As(III) oxidation under light conditions at 3 different $\mathrm{pH}$ values (i.e. $\mathrm{pH} \mathrm{3,6}$ and 8) were investigated and presented in the following paragraph.

\subsection{Oxidation mechanisms under light conditions}

Electron spin resonance (ESR) spectroscopy, radical scavenging and nitrogen purging experiments were conducted to determine the nature of radicals involved at each $\mathrm{pH}$ value. In the presence of DMPO compound used in ESR experiments, $\mathrm{SO}_{3}{ }^{-}$seems to be the predominant radical in the first stage of radical chain reactions (see Figure S5). However, in the absence of DMPO (as in our reaction medium) and in the presence of oxygen, $\mathrm{SO}_{3}{ }^{-}$can be easily oxidized to $\mathrm{SO}_{5}{ }^{-}$(eq.7), thereby considerably mitigating the contribution of $\mathrm{SO}_{3}{ }^{-}$in our system.

In the scavenging experiments TBA was used to capture $\mathrm{HO} \bullet\left(k_{\mathrm{TBA}}, \mathrm{HO} \bullet=(3.8-7.6) \times 10^{8}\right.$ $\left.\mathrm{M}^{-1} \mathrm{~s}^{-1}[45]\right)$, whereas EtOH was used to capture $\mathrm{HO} \bullet$ and $\mathrm{SO}_{4}^{-} \bullet\left(\mathrm{EEtOH}_{\mathrm{HO}} \cdot=(1.8-2.8) \times 10^{9}\right.$ $\mathrm{M}^{-1} \mathrm{~s}^{-1}$ [46], $k_{\mathrm{EtOH}}$, so4-• $\left.=(1.6-6.2) \times 10^{7} \mathrm{M}^{-1} \mathrm{~s}^{-1}[47,48]\right) . \mathrm{N}_{2}$ was used to eliminate the effect of oxygen. Supposing that radicals $\left(\mathrm{HO} \bullet\right.$ or $\left.\mathrm{SO}_{4^{\bullet}}\right)$ and LMCT process are mainly involved in As oxidation, their contributions were calculated by using $k_{\text {app }}$ value estimated for each 
condition (see Table S3). Indeed, the contribution of $\mathrm{HO} \bullet$ was obtained from the difference in $k_{\text {app }}$ with and without addition of TBA, and that of $\mathrm{SO}_{4}{ }^{-}-$was obtained from the difference in $k_{\text {app }}$ with EtOH and with TBA. Generally, nitrogen gas purging system can eliminate the effect of oxygen and thus reduce the formation of radicals, and therefore the contribution of LMCT oxidation was obtained from the $k_{\text {app }}$ estimated under $\mathrm{N}_{2}$ purging (Figure 6). As $k_{\text {app }}$ in the presence of EtOH was higher than that under $\mathrm{N}_{2}$ purging, we may expect the generation of various radicals species such as $\mathrm{SO}_{5}{ }^{-}$. The likelihood of $\mathrm{SO}_{5}{ }^{-}$participation in $\mathrm{As}$ (III) oxidation is also supported by the fact that $\mathrm{EtOH}$ cannot effectively scavenge $\mathrm{SO}_{5}{ }^{-}$(rate constant $\left.<1 \times 10^{3} \quad \mathrm{M}^{-1} \mathrm{~s}^{-1}[49]\right)$.

The contributions of $\mathrm{HO} \bullet$ and $\mathrm{SO}_{4}{ }^{-} \bullet$ decreased with $\mathrm{pH}$ increasing. For $\mathrm{SO}_{4}{ }^{-} \bullet$, this observation is consistent with the classical Fenton system, in which the performance of radical-involved oxidation process decays with $\mathrm{pH}$ increasing due to the precipitation of ferrous or ferric ions [50,51]. Indeed, the aqueous concentrations of $\mathrm{Fe}(\mathrm{II})$ decreased with $\mathrm{pH}$ increasing (Figure S6), consistently with the distribution diagram of Fe(II) species vs $\mathrm{pH}$ [52]. For $\mathrm{HO}$, part of dissolved $\mathrm{Fe}(\mathrm{III})$ can be complexed with $\mathrm{OH}^{-}$, forming $\mathrm{Fe}(\mathrm{III})-\mathrm{OH}$ complex under acidic conditions and then generating $\mathrm{HO} \bullet$ according to Eq. (13). When $\mathrm{pH}$ increases, dissolved Fe precipitated causing a decrease of $\mathrm{HO} \bullet$ generation.

$$
\mathrm{FeOH}^{2+}+h v \rightarrow \mathrm{Fe}^{2+}+\mathrm{HO} \cdot[53]
$$

On the other hand, generation of $\mathrm{HO} \bullet$ through $\mathrm{SO}_{4}{ }^{-} \cdot$ under acidic conditions is supposed to be lower than under basic conditions according to eq. (9) and eq. (10). However, the latter did not affect significantly the overall generation rate.

Under $\mathrm{N}_{2}$ purging, As(III) oxidation was observed at all tested $\mathrm{pH}$ values. At near-neutral 
conditions, Fe(III) mainly occurred as CFH and As(III)-sorbed species may undergo oxidation through LMCT. As CFH formed more easily with the increase in $\mathrm{pH}$, more As(III) underwent oxidation at $\mathrm{pH} 8$ than at $\mathrm{pH}$ 6. It is noteworthy that at $\mathrm{pH} 3$ (dark) under nitrogen purging, As(III) oxidation was not completely inhibited (Figure S7). This was not caused by LMCT because of the absence of visible light. According to Eq. (6), $\mathrm{SO}_{3}{ }^{-} \cdot$ generation is not dependent on the presence of oxygen, whereas the occurrence of $\mathrm{SO}_{3}{ }^{-}$can generate dithionate $\left(\mathrm{S}_{2} \mathrm{O}_{6}{ }^{2-}\right)$ (Eq. (14)) [54] and then oxidize As(III). To confirm this hypothesis, $\mathrm{Na}_{2} \mathrm{~S}_{2} \mathrm{O}_{5}$ was used as the source of $\mathrm{S}_{2} \mathrm{O}_{6}{ }^{2-}$. In the presence of oxygen, $\mathrm{Na}_{2} \mathrm{~S}_{2} \mathrm{O}_{5}$ is easily oxidized to $\mathrm{Na}_{2} \mathrm{~S}_{2} \mathrm{O}_{6}$. In order to exclude other factors, Fe(III) and irradiation were removed in this experiment. As shown in Figure S8, a small fraction of As(III) was oxidized, suggesting that As(III) oxidation was partly caused by $\mathrm{S}_{2} \mathrm{O}_{6}{ }^{2-}$. Additional experiments conducted at $\mathrm{pH} 6$ and 8 under dark anoxic conditions (Figure S7) showed a small fraction oxidized at pH 6 and negligible oxidation at pH 8, confirming the role of $\mathrm{S}_{2} \mathrm{O}_{6}{ }^{2-}$ in $\mathrm{As}$ (III) oxidation at $\mathrm{pH}$ 6. Under acidic conditions, the presence of oxygen had no obvious influence on $\mathrm{S}_{2} \mathrm{O}_{6}{ }^{2-}$ generation [55], suggesting that $\mathrm{S}_{2} \mathrm{O}_{6}{ }^{2-}$ contributes to As(III) oxidation even under acid oxic conditions. However, $\mathrm{SO}_{3}{ }^{\bullet}$ tends to react with DO under near-neutral and basic conditions (Eq. (7)), preventing the generation of $\mathrm{S}_{2} \mathrm{O}_{6}{ }^{2-}$. $\mathrm{SO}_{3}{ }^{-} \bullet+\mathrm{SO}_{3}{ }^{-} \bullet \mathrm{S}_{2} \mathrm{O}_{6}{ }^{2-} \quad k_{14}=1.8 \times 10^{8} \mathrm{M}^{-1} \mathrm{~s}^{-1} \quad[54]$

Because the contributions of $\mathrm{S}_{2} \mathrm{O}_{6}{ }^{2-}(<6 \%$ at $\mathrm{pH} 3)$ and of LMCT (due to the low amount of $\mathrm{CFH}$ at low $\mathrm{pH}$ ) are supposed to be low, these two pathways were ignored in our calculations at $\mathrm{pH} 3$ (Figure 6). In addition, the contribution of $\mathrm{CFH}$ must be considered as roughly estimated under acid or neutral conditions (Figure 6), because the role of $\mathrm{S}_{2} \mathrm{O}_{6}{ }^{2-}$ (even minor) has not been taken into account. 
To obtain further insights into the oxidation mechanism in the iron(III)/sulfite system, we investigated effect of phosphate at different $\mathrm{pH}$. Estimated $k_{\text {app }}$ values for each condition are plotted against phosphate concentration in Figure 7. The presence of phosphate led to a decrease in $k_{\text {app }}$ regardless of the $\mathrm{pH}$ tested. $\mathrm{As}^{\mathrm{PO}_{4}}{ }^{3-}$ has an atomic structure similar to that of arsenic, it can compete with As(III) for adsorption onto CFH formed at near-neutral $\mathrm{pH}$ and can completely inhibit As(III) oxidation [34]. However in iron(III)/sulfite system, phosphate could not completely inhibit oxidation at pH 6 and 8, suggesting that other oxidation processes may occur under near-neutral conditions. Moreover, the decrease in $k_{\text {app }}$ at $\mathrm{pH} 3$ implies that phosphate may also compete with sulfite in complexing with dissolved iron. Inspection of Table S3 and Figure 7 reveals that the contribution of LMCT at pH 6 is smaller than the inhibition extent of As oxidation in the presence of phosphate. This observation suggests that phosphate may inhibit As(III) oxidation by affecting both LMCT process and chain reactions of dissolved Fe. At pH 8, no significant difference was observed probably because of the low percentage of dissolved Fe at this $\mathrm{pH}$ value.

\subsection{Sequential experiments for higher-scale applications}

Sequential experiments were performed with multiple additions of As(III) and sulfite to evaluate the catalytic capacity of iron(III)/sulfite system in arsenic removal. An experiment using multiple additions of sulfite was also conducted on water contaminated with a high concentration of arsenic.

\subsubsection{Sequential addition of As(III) and arsenic(III)/sulfite}

A As(III) solution or As(III)-sulfite mixture was sequentially added to reaction solution 
every 20 min (Figure 8). Generally, the extent of oxidation decreased in both cases, but runs with additional sulfite showed higher efficiency in arsenic oxidation. In contrast to Fe, which is recycled under irradiation (i.e. reduction to $\mathrm{Fe}(\mathrm{II})$ and then oxidation to $\mathrm{Fe}(\mathrm{III})$ ), sulfite is not recyclable as it irreversibly transforms into sulfate. Therefore, additional sulfite is necessary to promote sequential treatment. In the experiment without sequential addition of sulfite, the oxidation of additional As(III) might be caused by LMCT process. In both cases, the generated $\mathrm{As}(\mathrm{V})$ can sorb onto $\mathrm{CFH}$ and then saturate the reactive surface sites, thus decreasing the overall oxidation efficiency.

\subsubsection{High initial concentration of As(III)}

In some regions, the maximum level of As contamination reach some $\mathrm{mg} \mathrm{L}^{-1}$ concentrations [56]. Therefore, the removal of high concentrations of arsenic merits investigation from an environmental point of view. Reactions with high As(III) concentration

(66.7 $\mu \mathrm{M}=5 \mathrm{mg} \mathrm{L}^{-1}$ ) were conducted (results are shown in Figure 9). Without additional sulfite, approximately 43\% of $\mathrm{As}(\mathrm{III})$ was oxidized after 120 min reaction, while up to $77 \%$ was oxidized when $2.5 \mathrm{~mL}$ of $20 \mathrm{mM}$ sulfite solution was added to reaction solution every $20 \mathrm{~min}$. As mentioned above, the consumption of sulfite lowered the efficiency of As(III) oxidation; thus, additional sulfite was needed to enable removal of higher amounts of arsenic. Furthermore, the first addition of sulfite significantly improved As removal, but this effect became less important with further additions probably because of precipitation of iron and adsorption of generated $\mathrm{As}(\mathrm{V})$ on $\mathrm{CFH}$.

\section{Conclusions}

Our results showed the high efficiency of the iron(III)/sulfite system in As(III) removal 
under visible light and sunlight. Our findings suggested multiple pathways to explain the oxidation of As(III) into As(V) in iron(III)/sulfite system. We have notably demonstrated that the mechanism of As(III) oxidation involved hydroxyl and oxysulfur radicals. CFH formed at near-neutral $\mathrm{pH}$ can sorb and then oxidize As(III) by electron transfer from As(III) to Fe(III) induced by absorption of radiation during LMCT process. Under acidic and anoxic conditions, $\mathrm{S}_{2} \mathrm{O}_{6}{ }^{2-}$ can also be formed and thus contribute to As(III) oxidation.

A high dosage of sulfite can inhibit As(III) oxidation, but a deficiency in sulfite may decrease the oxidation rate. Experiments using multiple additions of As(III) or arsenic(III)-sulfite mixtures showed the importance of sulfite addition in increasing the

efficiency of As(III) removal. The visible light/iron(III)/sulfite system and centrifugal treatment could effectively remove arsenic under near-neutral conditions. All these results imply that the sunlight/iron(III)/sulfite system is a cost-effective process for arsenic removal in contaminated waters.

\section{Acknowledgements}

This work was supported by the National Natural Science Foundation of China (Nos. 21077080 and 21477090). We gratefully acknowledge the Chinese Scholarship Council of PR China for providing financial support for XU J. to stay at the ENSCR - Rennes University, France. 


\section{References}

[1] J.H. Huang, E. Matzner, Sci. Total Envir. 377.2 (2007) 308-318.

[2] C.K. Jain, I. Ali, Water Res. 34.17 (2000) 4304-4312.

[3] M. Sadiq, Water Air Soil Polluti. 93.1-4 (1997) 117-136.

[4] Z. Wang, R.T. Bush, L.A. Sullivan,C. Chen, J. Liu, Environ. Sci. Technol. 48.7 (2014) 3978-3985.

[5] Z. Wang, R.T. Bush, L.A. Sullivan, J. Liu, Environ. Sci. Technol. 47.12 (2013) 6486-6492.

[6] S.J. Hug, Stephan, O. Leupin, Environ. Sci. Technol. 37.12 (2003) 2734-2742.

[7] M. Bissen, F.H. Frimmel, Acta hydrochimica et hydrobiologica. 31.2 (2003) 97-107.

[8] T.S. Choong, T.G. Chuah, Y. Robiah, F.G. Koay, I. Azni, Desalination 217.1 (2007) 139-166.

[9] S. Nishida, M. Kimura, J. Chem. Soc. Dalton Trans. 2 (1989) 357-360.

[10] Z. Wang, R.T. Bush, J. Liu, Chemosphere, 93.9 (2013)1936-1941.

[11] L. Zhou, W. Zheng, Y. Ji, J. Zhang, C. Zeng, Y. Zhang, Q. Wang, X. Yang, J. Hazard. Mater. 263 (2013) 422-430.

[12] S. Yoon, J.H. Lee, Environ. Sci. Technol. 39.24 (2005) 9695-9701.

[13] J. Ryu, W. Choi, Environ. Sci. Technol. 40.22 (2006) 7034-7039.

[14] M.T. Emett, G.H. Khoe, Water Res. 35.3 (2001) 649-656.

[15] S.J. Hug, L. Canonica, M. Wegelin, D. Gechter and U. von Gunten, Environ. Sci. Technol. 35.10 (2001) 2114-2121.

[16] B. Neppolian, A. Doronila, M. Ashokkumar, Water Res. 44.12 (2010) 3687-3695. 
[17] J. Sánchez, B. Butter, B.L. Rivas, L. Basáez, P. Santander, J. Appl. Electrochem. 45.2 (2015) 151-159

[18] B.D. Kocar, W.P. Inskeep, Environ. Sci. Technol. 37.8 (2003) 1581-1588.

[19] S.H. Yoon, J.H. Lee, J. Ind. Eng. Chem., 13.1 (2007) 97-104.

[20] P.K. Dutta, S.O. Pehkonen, V.K. Sharma, A.K. Ray, Environ. Sci. Technol. 39.6 (2005) $1827-1834$.

[21] R. Woods, I.M. Cutoff, E.J. Meehan, J. Am. Chem. Soc. 85.16 (1963) 2385-2390.

[22] R. Woods, I.M. Kolthoff, E.J. Meehan, J. Am. Chem. Soc. 85.21 (1963) 3334-3337.

[23] U.K. Klaning, B.H.J. Bielski, K. Sehested, Inorg. Chem. 28.14 (1989) 2717-2724.

[24] S.Y. Nishida, M. Kimura, Inorg. Chim. Acta. 174 (1990) 231-235.

[25] B. Neppolian, E. Celik, H. Choi, Environ. Sci. Technol. 42.16 (2008) 6179-6184.

[26] Y. Guo, X. Lou, C. Fang, D. Xiao, Z. Wang, J. Liu, Environ. Sci. Technol. 47.19 (2013) 11174-11181.

[27] L. Chen, X. Peng, J. Liu, J. Li, F. Wu, Ind. Eng. Chem. Res. 51.42 (2012) 13632-13638.

[28] L. Zhang, L. Chen, M. Xiao, L. Zhang, F. Wu, L. Ge. Ind. Eng. Chem. Res. 52.30 (2013) 10089-10094.

[29] D. Zhou, L. Chen, C. Zhang, Y. Yu, L. Zhang, F. Wu. Water Res. 57 (2014) 87-95.

[30] D. Zhou, H. Zhang, L. Chen. J. Chem. Technol. Biotechnol. 90.5 (2014) 775-779.

[31] T. Nishimura, Q. Wang, Y. Umetsu, in: J.E. Dutrizac, G.B. Harris (Eds.), Iron Control and Disposal, Ottawa, CIM, Montreal, Canada, 1996, pp. 535-548.

[32] G.H. Khoe, M. Zaw, U.S. Patent No. 6,558,556. (2003).Washington, DC: U.S. Patent and Trademark Office. 
[33] W. Zhang, P. Singh, D.M. Muir, Proc. Minor Elem. (2000) 333-343.

[34] J. Xu, J. Li, F. Wu, Y. Zhang, Environ. Sci. Technol. 48.1 (2013) 272-278.

[35] S. Sakthivel, B. Neppolian, M.V. Shankar, B. Arabindoo, M. Palanichamy, V. Murugesan, Solar Energ. Mater. Solar Cells. 77.1 (2003) 65-82.

[36] Y. Wang, J. Xu, J. Li, F. Wu, J. Hazard. Mater. 260 (2013) 255-262.

[37] C. Ren, H. Peng, W. Huang, Y. Wang, F. Wu, Fresen. Environ. Bull. 20.4 (2011) 1069-1074.

[38] C.G. Yuan, K. Zhang, Z. Wang, G. Jiang, J. Anal. Atom. Spectrom. 25.10 (2010) $1605-1611$

[39] L.C. Roberts, S.J. Hug, T. Ruettimann, M.M. Billah, A.W. Khan, M.T. Rahman, Environ. Sci. Technol. 38.1 (2004) 307-315.

[40] B.A. Manning, S.E. Fendorf, S. Goldberg, Environ. Sci. Technol. 32.16 (1998) 2383-2388.

[41] Y. Zhang, J. Zhou, C. Li, S. Guo, G. Wang, Ind. Eng. Chem. Res. 51.3 (2012) 1158-1165.

[42] I. Grgićc, P. Marjeta, B. Mirko, J. Atmos. Chem. 33.1 (1999) 89-102.

[43] D.T.F. Kuo, D.W. Kirk, C.Q. Jia, J. Sulfur Chem. 27.5 (2006) 461-530.

[44] P.H. Wine, Y. Tang, R.P. Thorn, J.R. Wells, D.D.J. Davis, Geophys. Res.-Atmos. 94.D1 (1989) 1085-1094.

[45] G.P. Anipsitakis, D.D. Dionysiou, Environ. Sci. Technol. 38.13 (2004) 3705-3712.

[46] G.E. Adams, J.W. Boag, B.D. Michael, Trans. Faraday Soc. 61 (1965) 1417-1424.

[47] H. Eibenberger, S. Steenken, P. O'Neill, D. Schulte-Frohlinde, J. Phys. Chem. 82.6 (1978) 749-750.

[48] L. Dogliotti, E. Hayon, J. Phys. Chem. 71.8 (1967) 2511-2516. 
[49] E. Hayon, A. Treinin, J. Wilf, J. Amer. Chem. Soc. 94.1 (1972) 47-57.

[50] X. Xue, K. Hanna, M. Abdelmoula, N. Deng, Appl. Catal. B-Environ. 89.3 (2009) 432-440.

[51] X. Xue, K. Hanna, N. Deng, J. Hazard. Mater. 166.1 (2009) 407-414.

[52] D.W. King, Environ. Sci. Technol. 32.19 (1998) 2997-3003.

[53] F. Wu, N.S. Deng, Chemosphere. 41.8 (2000) 1137-1147.

[54] W. JohnáMcElroy, J. Chem. Soc. Faraday Trans. 88.11(1992) 1525-1530.

[55] C. Brandt, R. Van Eldik, Atmos. Environ. 31.24 (1997) 4247-4249.

[56] S.R. Panthi, S. Sharma, A.K. Mishra, J. Sci. Eng. Technol. 2.1 (2006) 1-11. 


\section{Figures captions}

Figure 1. Changes in As(III) concentration over time in different systems. Initial conditions: $\mathrm{pH}=6,[\mathrm{As}(\mathrm{III})]=6.67 \mu \mathrm{M},[\mathrm{Fe}(\mathrm{III})]=0.1 \mathrm{mM},\left[\mathrm{Na}_{2} \mathrm{SO}_{3}\right]=0.1 \mathrm{mM}$.

Figure 2. Changes in As(III) concentration over time under solar power. Solid lines are fitted to a pseudo-first-order curve for the first $5 \mathrm{~min}$. Initial conditions: $\mathrm{pH}=6,[\mathrm{As}(\mathrm{III})]=6.67 \mu \mathrm{M}$, $[\mathrm{Fe}(\mathrm{III})]=0.1 \mathrm{mM},\left[\mathrm{Na}_{2} \mathrm{SO}_{3}\right]=0.1 \mathrm{mM}$.

Figure 3. Effect of sulfite dosage on the initial apparent rate constant of As(III) oxidation ( $k_{\text {app }}$ ). The curve is only a visual guide. Initial conditions: $\mathrm{pH}=6,[\mathrm{As}(\mathrm{III})]=6.67 \mu \mathrm{M},[\mathrm{Fe}(\mathrm{III})]=0.1$ mM.

Figure 4. Effect of initial $\mathrm{pH}$ value on the initial apparent rate constant of As(III) oxidation ( $\left.k_{\mathrm{app}}\right)$ under dark and light conditions. Initial conditions: $[\mathrm{As}(\mathrm{III})]=6.67 \mu \mathrm{M},[\mathrm{Fe}(\mathrm{III})]=0.1 \mathrm{mM}$, $\left[\mathrm{Na}_{2} \mathrm{SO}_{3}\right]=0.1 \mathrm{mM}$.

Figure 5. Effect of the presence of sulfite on the initial apparent rate constant of As(III) oxidation $\left(k_{\mathrm{app}}\right)$ at various initial $\mathrm{pH}$ values. Initial conditions: $[\mathrm{As}(\mathrm{III})]=6.67 \mu \mathrm{M},[\mathrm{Fe}(\mathrm{III})]=$ $0.1 \mathrm{mM},\left[\mathrm{Na}_{2} \mathrm{SO}_{3}\right]=0.1 \mathrm{mM}$.

Figure 6. Contribution of different pathways to As(III) oxidation at various initial pH values.

Figure 7. Inhibitory effect of phosphate at different concentrations on the initial apparent rate constant of As(III) oxidation ( $\left.k_{\mathrm{app}}\right)$ at various $\mathrm{pH}$ values. The curves are only a visual guide. Initial conditions: $[\mathrm{As}(\mathrm{III})]=6.67 \mu \mathrm{M},[\mathrm{Fe}(\mathrm{III})]=0.1 \mathrm{mM},\left[\mathrm{Na}_{2} \mathrm{SO}_{3}\right]=0.1 \mathrm{mM}$.

Figure 8. Changes in As(III) concentration over time in sequential experiments. Initial conditions: $\mathrm{pH}=6,[\mathrm{As}(\mathrm{III})]=6.67 \mu \mathrm{M},[\mathrm{Fe}(\mathrm{III})]=0.1 \mathrm{mM},\left[\mathrm{Na}_{2} \mathrm{SO}_{3}\right]=0.1 \mathrm{mM}$, multiple additions of $2.5 \mathrm{~mL} 1.34 \mathrm{mM}$ As(III) and $2.5 \mathrm{~mL} 20 \mathrm{mM} \mathrm{SO}_{3}{ }^{2-}$ solutions every 20 minutes. 
Figure 9. Changes in As(III) concentration over time at high arsenic levels. Initial conditions: $\mathrm{pH}=6,[\mathrm{As}(\mathrm{III})]=66.7 \mu \mathrm{M},[\mathrm{Fe}(\mathrm{III})]=0.1 \mathrm{mM},\left[\mathrm{Na}_{2} \mathrm{SO}_{3}\right]=0.1 \mathrm{mM}$, multiple additions of 2.5 $\mathrm{mL} 20 \mathrm{mM} \mathrm{SO}_{3}{ }^{2-}$ solution. Arrows indicate the time of sulfite addition. 


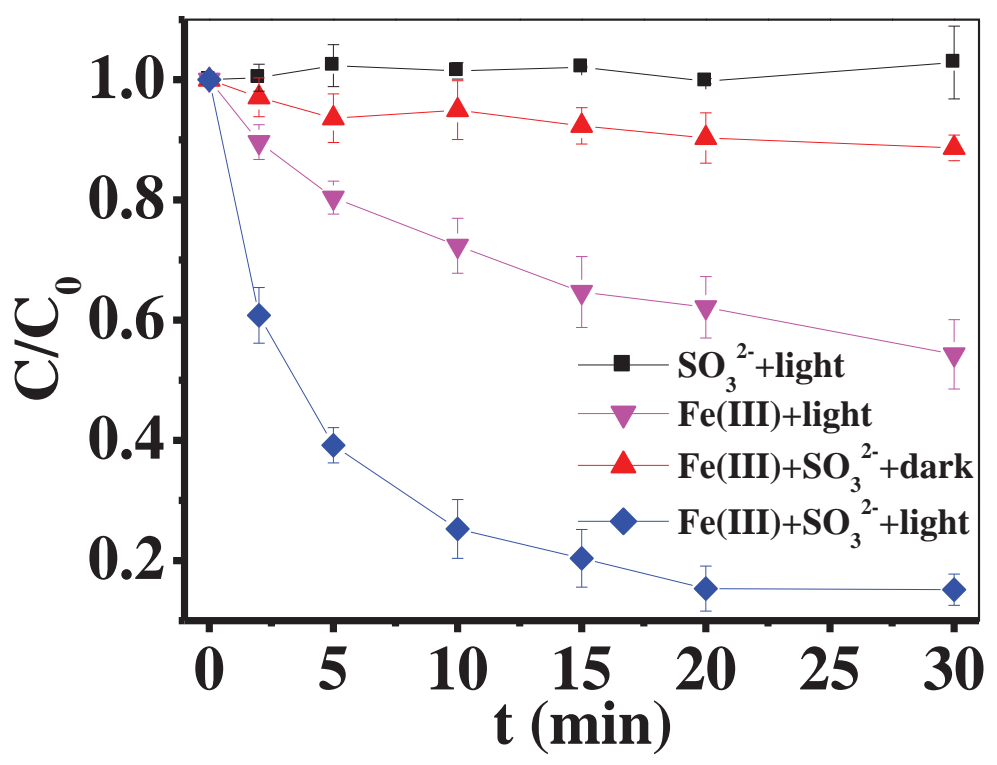

Figure 1. 


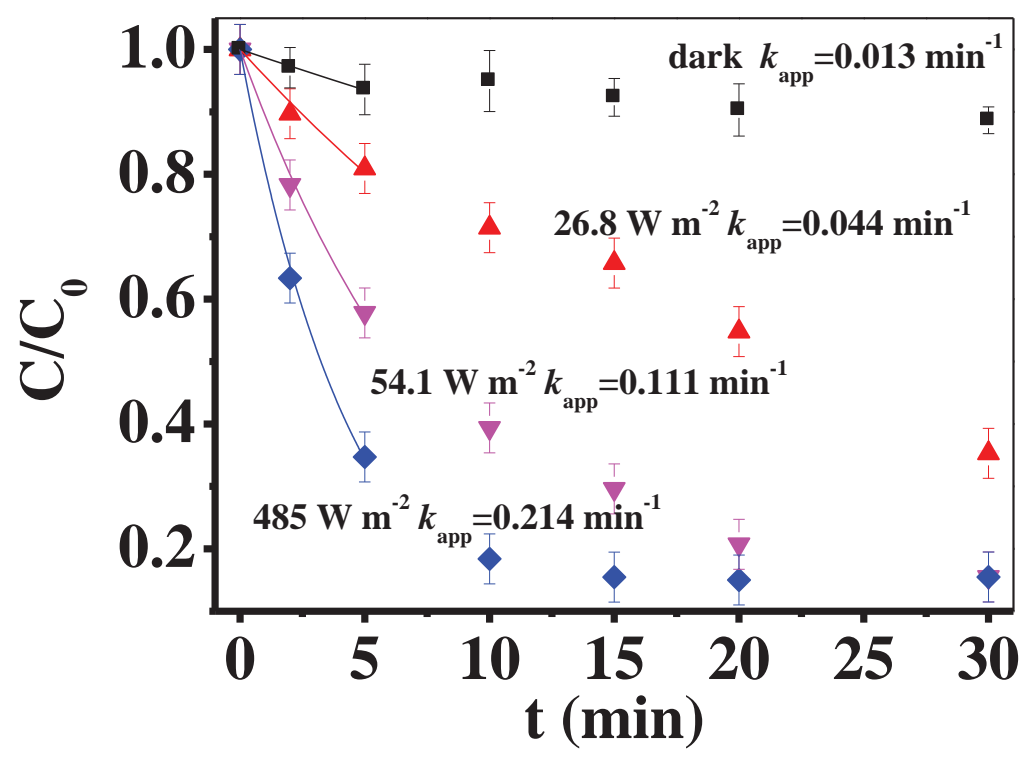

Figure 2. 


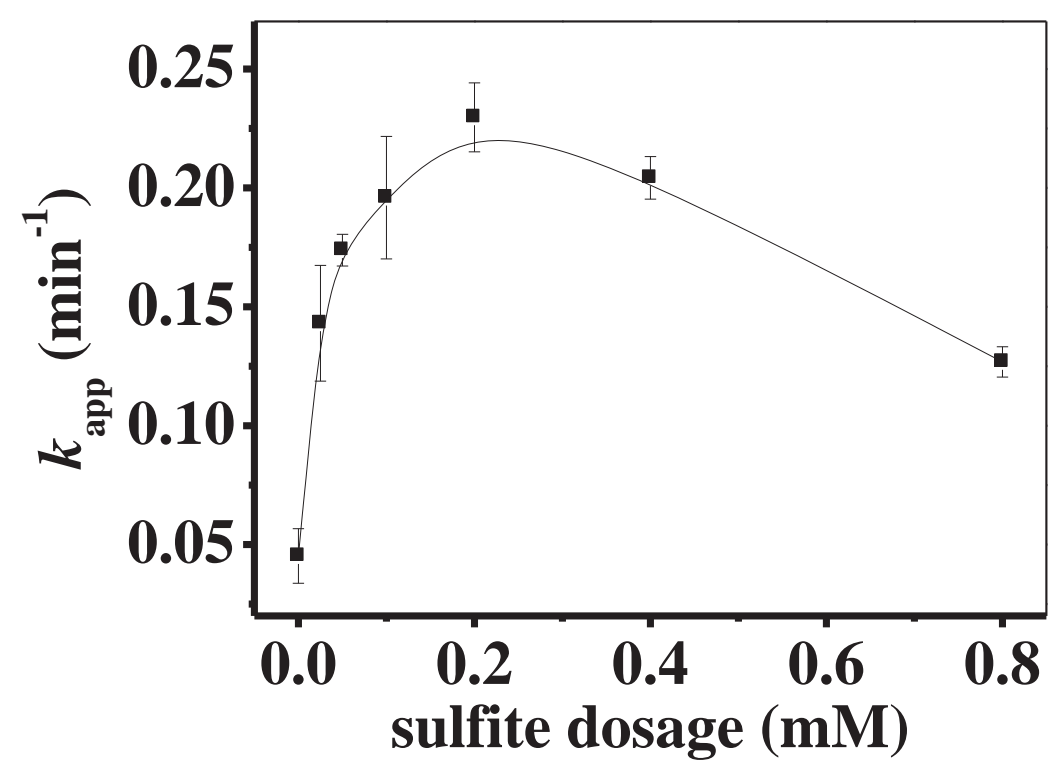

Figure 3. 


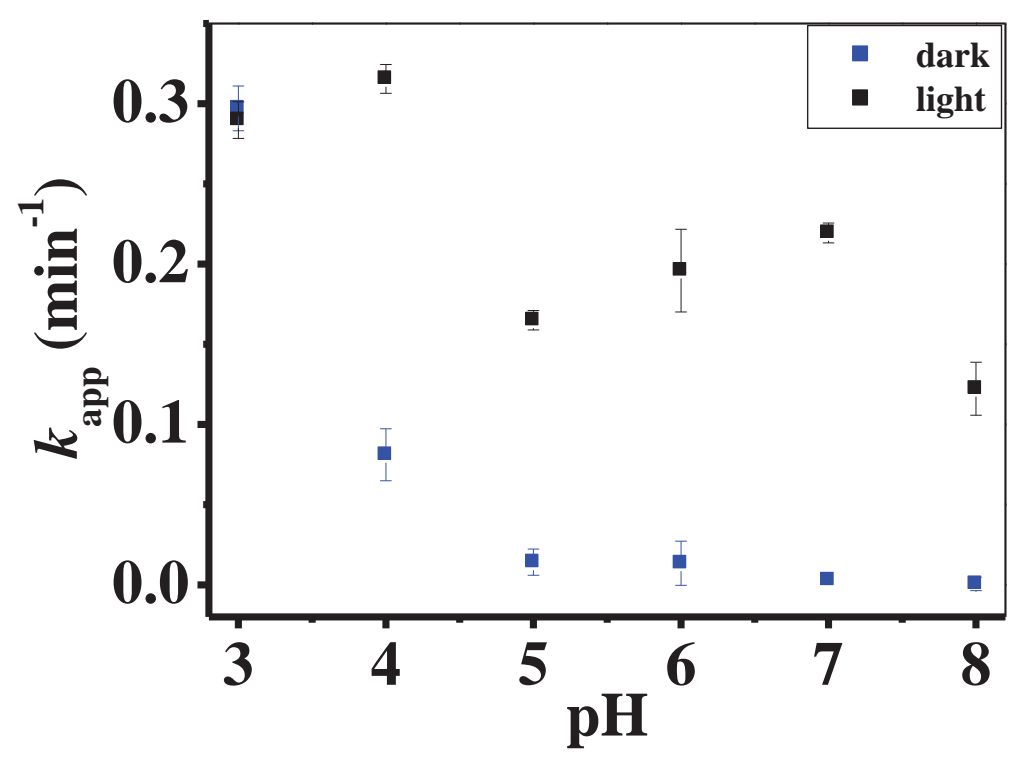

Figure 4. 


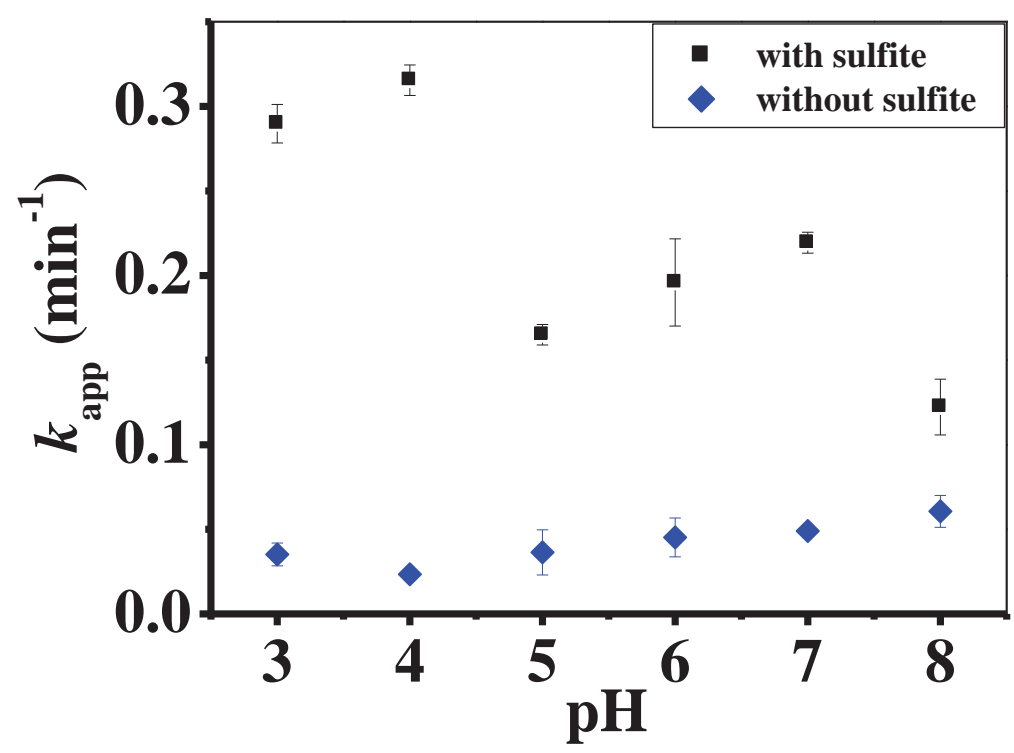

Figure 5. 


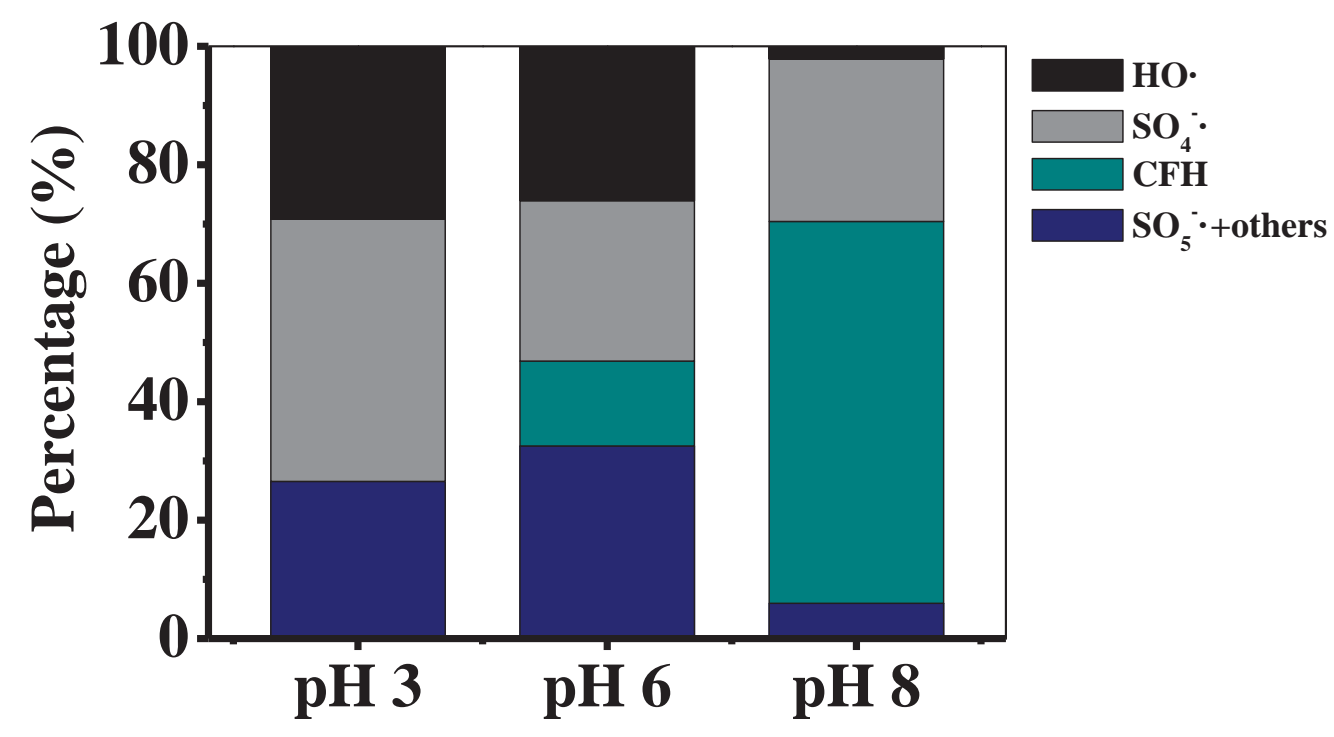

Figure 6. 


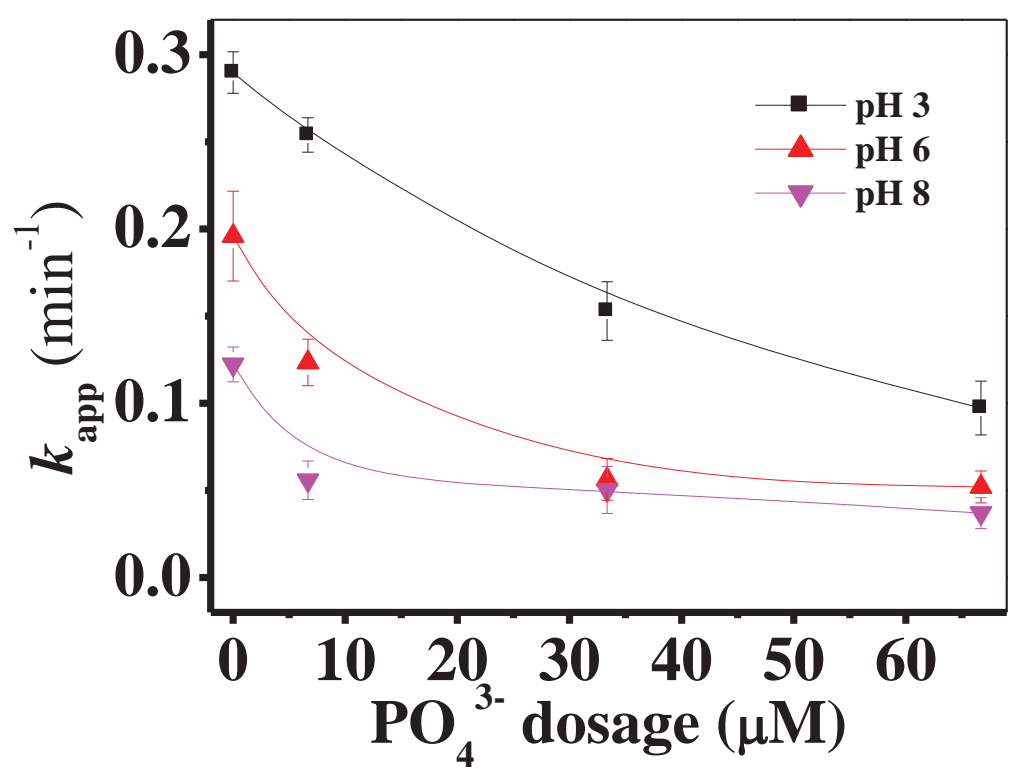

Figure 7. 


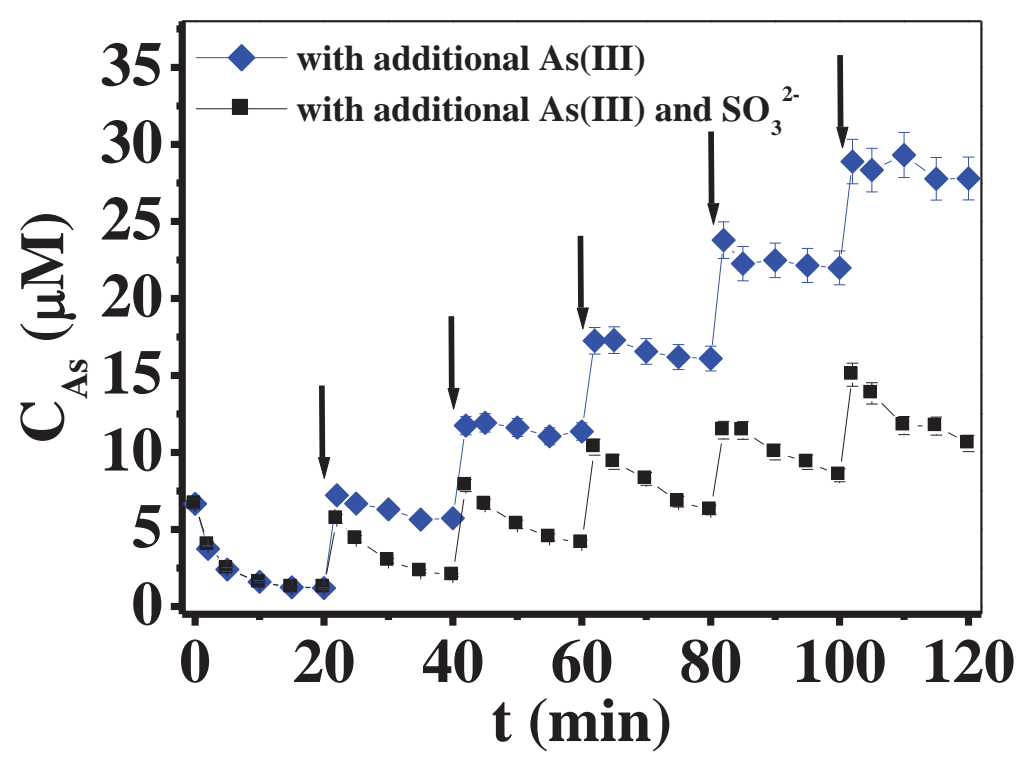

Figure 8. 


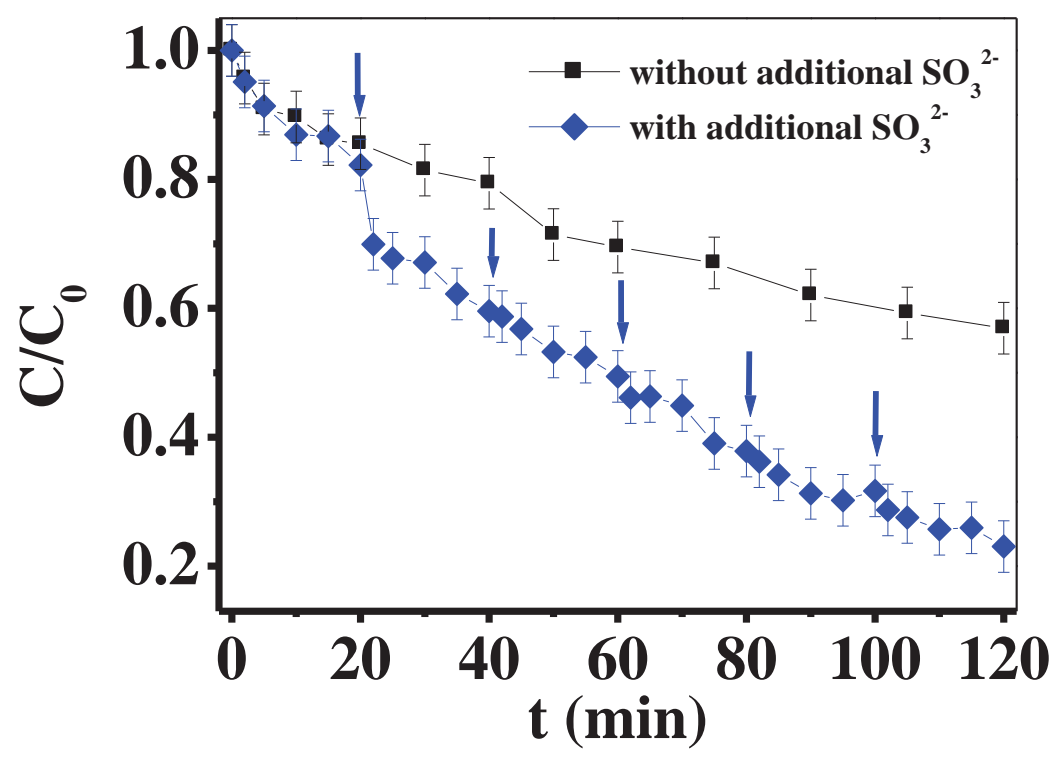

Figure 9. 


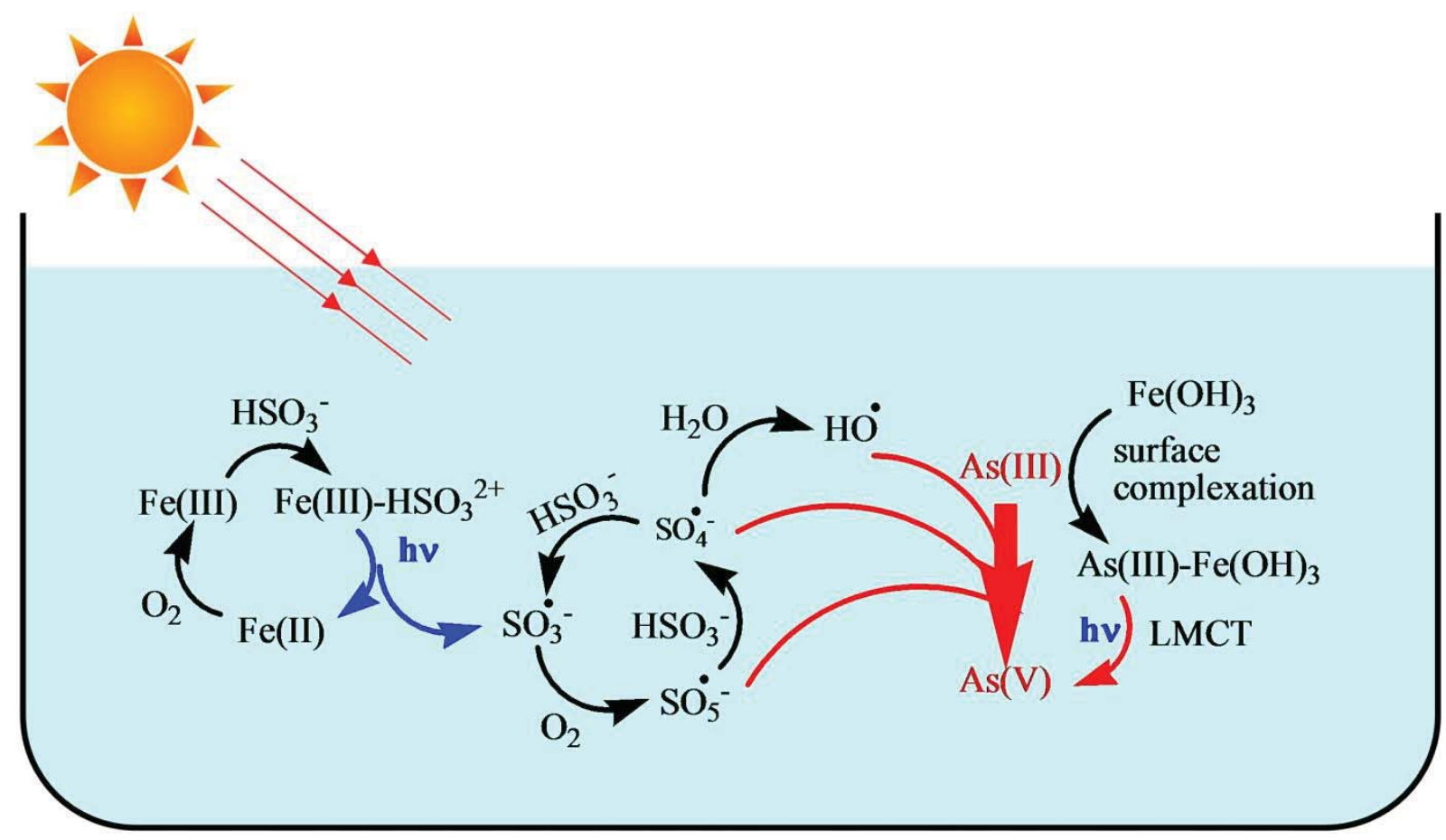

Scheme 1

Scheme 1. Proposed pathways for As(III) oxidation in iron(III)/sulfite-visible light system at near-neutral condition. 